\title{
Distinct Cytokine Profiles in Patients with Oligoarticular Juvenile Idiopathic Arthritis after in Vitro Blockade of Interleukin (IL)-1 and Tumor Necrosis Factor (TNF)- $\alpha$
}

\author{
Martina Kirchner, Leo Strothmann, Anja Sonnenschein, Wilma Mannhardt-Laakmann* \\ Division of Pediatric Immunology and Rheumatology, Department of Pediatrics, University Hospital of Mainz, \\ Mainz, Germany \\ Email: Martina.kirchner@unimedizin-mainz.de, leo.strothmann@gmail.com, A.Sonnenschein@gmx.de, \\ *wilma.mannhardt-laakmann@unimedizin-mainz.de
}

Received 4 June 2014; revised 4 July 2014; accepted 5 August 2014

Copyright (C) 2014 by authors and Scientific Research Publishing Inc.

This work is licensed under the Creative Commons Attribution International License (CC BY). http://creativecommons.org/licenses/by/4.0/

(c) () Open Access

\section{Abstract}

Oligoarticular juvenile idiopathic arthritis (oJIA) is an antigen-driven and lymphocyte-mediated autoimmune disorder with irregularity in the adaptive immune system. Auto reactive $T$ cells, activated by cartilage-derived auto antigens, produce pro-inflammatory cytokines as IFN- $\gamma$ and IL-17. Failure of regulatory $T$ cells leads to decreased anti-inflammatory cytokine IL-10 production and results in the loss of immune tolerance. This activation of innate and adaptive immunity stimulates the release of pro-inflammatory cytokines IL-1, IL-6 and TNF- $\alpha$. Thus, inhibition of these cytokines is considered as an appropriate therapeutic strategy for oJIA. The aim of this study was to investigate whether the blockade of a single cytokine pathway in the present cytokine setting causes an unfavourable imbalance in the cytokine system or whether the blockade is sufficient to suppress the inflammatory condition. We examined the cytokine secretion after in vitro inhibition of IL-1 and TNF- $\alpha$ of patients with oJIA and healthy subjects. This single center cohort study consisted of oJIA affected children and control subjects. Cytokine profiles from cell culture supernatants were examined with multiplex fluorescent bead immunoassay by flow cytometry. Adalimumab prevents highly effective and very selective effect of the cytokine TNF- $\alpha$. Due to its structure, the mode of action of etanercept is difficult to display. In addition, adalimumab and etanercept appear in vitro suppressive to IFN- $\gamma$. The efficiency of both substances is particularly supported by the increased secretion of anti-inflammatory cytokine IL-4. In contrast, anakinra unselectively inhibits the pro-inflammatory macrophage cytokines. To conclude, our observations suggest that inhibition of IL-1 or TNF- $\alpha$ may contribute to the unselective decline of other pro-inflammatory cytokines in oJIA patients. The selective anti-inflammatory effect of cytokine inhibitors is most

\footnotetext{
*Corresponding author.
} 
likely supported by an increase of IL-4 or IL-10. It still remains to be elucidated whether the reduced IFN- $\gamma$ secretion is maybe causative for the increased susceptibility to infections with opportunistic pathogens.

\title{
Keywords
}

\author{
Oligoarticular Juvenile Idiopathic Arthritis, Pro-Inflammatory Cytokines, Cytokine Inhibition
}

\section{Introduction}

Oligoarticular JIA refers to a group of chronic childhood arthropathies of unknown aetiology. This type of juvenile arthritis is regarded as T helper 1 (Th1) cell-mediated inflammatory disorder, mainly based on the abundance of activated Th1 cells in the inflamed synovium and the pathogenetic role of pro-inflammatory cytokines that are produced by Th1 cell stimulated monocytes, macrophages and synovial fibroblasts [1]. Th1 cells also activate B cells to produce immunoglobulins, including rheumatoid factor (RF) and antinuclear antibodies (ANAs). ANAs, which are for the main part associated with early onset oligoarthritis, have been reported to react against different nuclear targets, none of which are specific for JIA. Although the precise mechanism leads to oJIA remains unclear, the overproduction of pro-inflammatory cytokines is thought to be responsible for the clinical manifestations of oJIA [2]-[4]. Modulation of these cytokines results in improvement of clinical outcome, which strongly suggests that these cytokines play important roles in oJIA [5]. Primary roles in the pathogenesis of oJIA have TNF- $\alpha$ and IL-1 which are produced by monocytes, macrophages and synovial fibroblasts. These cytokines are detected in synovial fluids or tissues of oJIA patients, and are known to stimulate mesenchymal cells to release tissue-destroying matrix metalloproteinases. Furthermore, IL- 1 and TNF- $\alpha$ also embarrass synovial fibroblasts from producing tissue inhibitors of metalloproteinases. Altogether, these dual actions seem to lead to joint damage [6]. Self-molecules, (e.g. S100 proteins) indicating synovial tissue damage amplify inflammatory arthritis [7]. Serum concentrations of S100A8/S100A9 proteins correlate well with the disease activity in children [8] [9].

At present it is still uncertain whether TNF- $\alpha$ gene polymorphisms (SNPs) influence disease susceptibility and treatment of JIA patients. An association between some TNF- $\alpha$ SNPs and adult rheumatoid arthritis susceptibility, severity and clinical response to anti-TNF- $\alpha$ treatment has been reported [10]-[13]. Furthermore, associations between TNF- $\alpha$ SNPs and subtypes of JIA have been found [12] [13]. The most frequently studied TNF- $\alpha$ SNP is located at -308 position, where the presence of the rare A allele was associated with a major gene expression, high level of TNF- $\alpha$ expression, and more aggressive JIA phenotypes [14]-[16]. The presence of the allele $-308 \mathrm{~A}$ is associated to JIA and to a poor prognosis. In addition, the $-308 \mathrm{G}$ genotype has been associated with better response to anti-TNF- $\alpha$ treatment in JIA patients, confirming adult data [17]. In some studies oligoarticular arthritis is significantly associated to the -238 SNP [10] [16] [18] [19].

Moreover, blocking TNF- $\alpha$ or IL-1 with either a soluble receptor fusion protein or monoclonal antibodies ameliorates disease activity of oJIA. IL-6 is a multifunction cytokine that has a wide range of biological activities and shows markedly elevated levels in oJIA patients [20].

Anakinra is a fully human IL-1 receptor antagonist, which blocks the biologic activity of naturally occurring IL-1, including inflammation and cartilage degradation associated with JIA, by competitively inhibiting the binding of IL-1 to the interleukin-1 type receptor, which is expressed in many tissues and organs.

Adalimumab is a TNF inhibitor, constructed from a fully human monoclonal antibody which binds to TNF- $\alpha$, preventing it from activating TNF receptors. TNF- $\alpha$ inactivation has proven to be important in downregulating the inflammatory reactions associated with autoimmune diseases and JIA.

Etanercept is a genetically engineered fusion protein consisting of two identical chains of the recombinant extracellular human TNF-receptor p75 monomer fused with the Fc domain of a human IgG1. Etanercept binds both TNF- $\alpha$ and lymphotoxin alpha and inhibits their activity [21]. This decreases inflammation in disorders mediated by excess TNF- $\alpha$.

These biologics decrease a patient's immune response and infections are a compelling concern in JIA patients treated with anti-IL-1 respectively anti-TNF- $\alpha$ agents [22]. The most common adverse effects reported for the 
IL-1 receptor antagonist anakinra are injection site reactions which are often mild and transient [23] and an increase in upper respiratory tract infections [24] [25]. Sharma and colleagues report other potential side effects including serious infections, neutropenia, nausea, influenza-like symptoms and production of anti-anakinra antibodies [26]. Rates of infections vary considerably between studies. The serious infections include severe bacterial infections, varicella-zoster infections [27] and rare cases of invasive fungal infections especially in areas endemic to these diseases such as histoplasmosis [28]. Reactivation of infectious diseases such as hepatitis B [29] and tuberculosis [30], and the occurance of opportunistic infections are reported [31] [32]. It is recommended that patients be tested for tuberculosis before starting treatment with TNF- $\alpha$ inhibiting drugs and annually thereafter [33]. Further compelling concerns are the induction of autoimmunity and possible malignancies [34]-[36].

We hypothesized that the enduring local inflammation in oJIA patients triggered by pathogen associated molecular patterns (PAMPS) such as LPS may correlate with levels of IL-1 and TNF- $\alpha$ yield of leukocytes. We therefore decided to investigate the cytokine secretion of peripheral leukocytes of oJIA patients after in vitro LPS stimulation as well as the cytokine levels of healthy individuals. Furthermore, we hypothesized that on the one hand, treatment with IL-1 and TNF- $\alpha$ inhibitors anakinra, adalimumab or etanercept may suppress inflammation, but on the other hand, it may cause an unfavourable imbalance in the cytokine system. The current study compared cytokine secretion of peripheral leukocytes of oJIA patients with healthy individuals after in vitro LPS stimulation, respectively inhibition of IL-1 and TNF- $\alpha$ using anakinra, adalimumab or etanercept.

\section{Methods}

\subsection{Patients and Samples}

This single center cohort study consisted of oJIA affected children and control subjects and was conducted in the period 2009-2011. All JIA patients fit the ILAR classification criteria for childhood arthritis and provided written informed consent before enrolment. Peripheral venous blood was drawn from 10 patients of our pediatric rheumatological outpatient clinic and from 15 similar gender non-related young adults to serve as healthy controls. The study protocol was approved by the institutional ethics committee (\#837.169.08).

\subsection{Patient Demographics}

Ten oJIA patients were enrolled after consent. Comprehensive clinical information was collected at each oJIA patient visit, including history, physical examination (including presence of fever, rash and joint count), and clinical laboratory values [leukocytes, erythrocyte sedimentation rate (ESR), soluble IL-2 receptor (IL-2R), C-reactive protein (CRP) and complement activity (CH-50)]. Clinical status at each visit was graded according to a scoring system developed by our group to grade severity of systemic disease manifestations or arthritis. Each sample was classified as "flare" (active disease; score of 5 or above) or "quiescence" (inactive disease; score of 0 ). All but two patients were under antiphlogistic (Naproxene) therapy, dependent upon their clinical symptoms. Characteristics of the study subjects are shown in Table 1.

\subsection{Isolation and Culture of Peripheral Mononuclear Cells (PBMCs)}

Freshly isolated heparinized whole blood was overlaid on an equal volume of Lymphocyte Separation Medium (PAA-Laboratories GmbH, Pasching, Austria), and centrifuged at $800 \times \mathrm{g}$ for $30 \mathrm{~min}$. The mononuclear cell ring, which contained PBMC, was obtained from the interface using a Pasteur pipette without disturbing the upper layer cells. The PBMCs were centrifuged again at $250 \times \mathrm{g}$ for $10 \mathrm{~min}$. The pelleted cells were then resuspended in $5 \mathrm{ml}$ phosphate buffered saline (DPBS, gibco, Paisley, UK). After washing, the pellets were suspended in RPMI 1640 medium containing 10\% human AB-Serum, penicillin $(100 \mathrm{U} / \mathrm{ml})$, streptomycin $(100 \mu \mathrm{g} / \mathrm{ml})$ and glutamine ( $2 \mathrm{mM}$; all reagents from PAA, Germany). Next, $1 \times 10^{6} \mathrm{PBMCs} /$ well were cultured in $200 \mu \mathrm{l}$ of the RPMI 1640 for $24 \mathrm{~h}$ in round bottom 96 well plates (BRAND, Wertheim, Germany).

\subsection{Co-Culture of PBMC with Gram-Negative Bacterial Endotoxin, Lipopolysaccharide (LPS)}

PBMC samples $\left(1 \times 10^{6} /\right.$ well) were incubated with $200 \mu \mathrm{l}$ of RPMI 1640 with LPS $(10 \mu \mathrm{g} / \mathrm{ml}$; InvivoGen, San 
Table 1. Patient demographics.

\begin{tabular}{cc}
\hline Number of samples analyzed patients/controls & $10: 15$ \\
Age at enrolment [median (range) years] & $13.4(0-26)$ \\
Age at onset [median (range) years] & $4.3(0-12)$ \\
Disease duration [median (range) years] & $4.7(1-11)$ \\
Disease activity & \\
No or low activity [n] & 9 \\
High activity/flare [n] & 1 \\
Leukocytes (/nl) & $7.94(5.2-12.0)$ \\
ESR (mm/h) & $84(3-92)$ \\
CRP (mg/l) & $18.5(1-68)$ \\
IL-2R (U/ml) & $674.3(435-1006)$ \\
CH-50 (U/ml) & $59.6(42-85)$ \\
Male/female & $4: 6$ \\
HLA B27 positive & 1 \\
ANA positive & 5 \\
Patients on & 0 \\
DMARDS & 2 \\
NSAIDS & \\
Steroids & \\
\hline
\end{tabular}

Diego, USA) at $37^{\circ} \mathrm{C}$ and $5 \% \mathrm{CO}_{2}$. After $24 \mathrm{~h}$ of culture, the supernatants were obtained and kept at $-20^{\circ} \mathrm{C}$ until use in the cytokine ELISA.

\subsection{Inhibition of IL-1 or TNF- $\alpha$ in PBMC by Anakinra, Etanercept and Adalimumab}

The BMC $\left(1 \times 10^{6} /\right.$ well) were incubated with $200 \mu$ RPMI 1640 containing LPS $(10 \mu \mathrm{g} / \mathrm{ml})$ and anakinra $(1$ $\mu \mathrm{g} / \mathrm{ml}$; Swedish Orphan Biovitrum AB, Stockholm, Sweden), etanercept (0, $1 \mu \mathrm{g} / \mathrm{ml}$; Wyeth Pharma, Münster, Germany) respectively adalimumab $\left(10 \mu \mathrm{g} / \mathrm{ml}\right.$; Abbott Laboratories, Chicago, Illinois, USA) for $24 \mathrm{~h}$ at $37^{\circ} \mathrm{C}$ and $5 \% \mathrm{CO}_{2}$. After $24 \mathrm{~h}$, the supernatants were obtained and kept at $-20^{\circ} \mathrm{C}$ until use in the cytokine ELISA.

\subsection{Multiplex Fluorescent Bead Immunoassay (ELISA) for Determination of Cytokine Profiles}

Two-colour flow cytometry was applied to cell culture supernatants of oJIA patients and healthy control subjects, to investigate the concentrations of Interleukin (IL)-12p70, Interferon (IFN)- $\gamma$, IL-2, IL-4, IL-5, IL-6, IL-8, IL-10, IL-17A, IL- $\beta$, Tumor necrosis factor (TNF)- $\alpha$ and TNF- $\beta$. All cytokines were measured by commercial kits, Human Th1/Th2 11plex FlowCytomix Kit and Human IL-17A simplex Kit (BenderMedSystems GmbH, Vienna, Austria) according to the manufacturer's instructions for the use of tubes.

In order to evaluate the change of cytokine production, we formed the ratio of the values of stimulated cell cultures with biological and the values of unstimulated cell cultures.

\subsection{Statistical Analysis}

Mann-Whitney $U$ test was used to compare data of healthy controls and oJIA patients. Only the values of $\mathrm{p}<$ 0.05 were considered to be statistically significant in all analyses. Statistical analysis was performed with commercial software (SPSS Statistics Software version 20.0; SPSS Inc.). 


\section{Results}

\subsection{Pro-Inflammatory Macrophage Cytokines IL-1, IL-6 and TNF- $\alpha$}

We examined the presence of twelve cytokines in leukocyte culture supernatants of 10 oJIA patients as well as 15 healthy individuals by flow cytometry analysis (multiplex fluorescent bead immunoassay).

In order to evaluate the change of cytokine production after LPS stimulation and inhibition by anakinra, etanercept or adalimumab, the ratio of the values of stimulated cell cultures with biologic and the values of unstimulated cell cultures was formed.

We stated that LPS stimulated leukocytes of oJIA patients secrete more IL-6 than healthy individuals. In contrast, LPS induced IL-1 and TNF- $\alpha$ production was generally higher in the control group (Figure 1). Furthermore, in healthy individuals a significant inhibition of IL-1 could be achieved by anakinra, while oJIA patients showed changed IL-1 levels to a lesser extent. Adalimumab also reduces IL-1 levels, but only slightly and in healthy individuals. Etanercept did not alter IL-1 levels. By the use of adalimumab the complete inhibition of TNF- $\alpha$ was attained equally in oJIA patients and healthy. Although etanercept shows an inhibitory effect on TNF- $\alpha$ in the control group it still seems to reinforce TNF- $\alpha$ secretion in oJIA patients. Besides, we observed the decline of TNF- $\alpha$ by anakinra in healthy individuals and the decline of IL-6 in both groups. In leukocyte cultures of oJIA patients and healthy subjects a moderate decrease of IL-6 could also be documented during treatment with etanercept. While adalimumab has no effect on IL-6 in oJIA patients, it acts suppressive in the control group.

\subsection{Pro-Inflammatory T Cell Cytokines IL-2, IL-8, IL-12p70, IL-17A, TNF- $\beta$ and IFN- $\gamma$}

As expected, we found after LPS stimulation no significant change in cytokine secretion concerning IL-2, IL-8, IL-12p70, IL-17A and TNF- $\beta$. Interestingly, stimulated leukocytes of healthy individuals secrete more IFN- $\gamma$ than leukocytes of oJIA patients. We discovered that anakinra considerably inhibits IFN- $\gamma$ in oJIA patients just as well as in healthy control subjects (Figure 2). For adalimumab we observed a similar effect. Etanercept also reduces IFN- $\gamma$ levels, but only in the control group.

\subsection{Anti-Inflammatory T Cell Cytokines IL-4, IL-5 and IL-10}

Regarding IL-5 secretion there was no change whatsoever detectable. Likewise, in healthy control subjects we

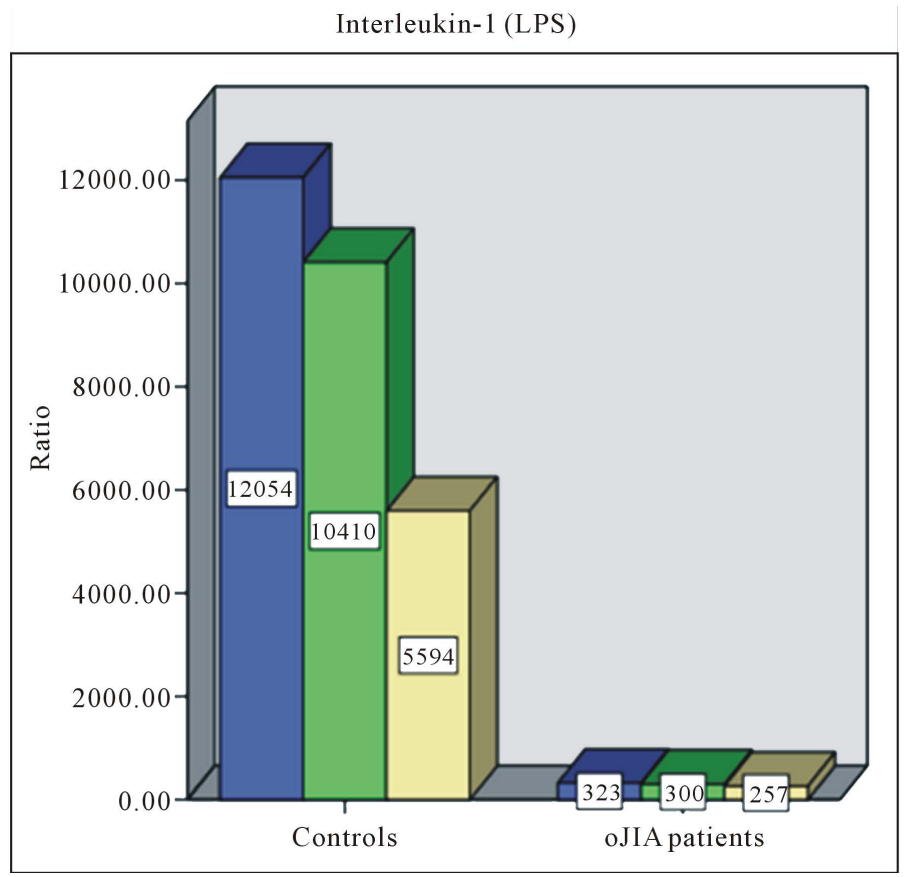

LPS stimulated/unstimulated

LPS stimulated adalimumab/unstimulated

LPS stimulated anakinra/unstimulated

(a) 


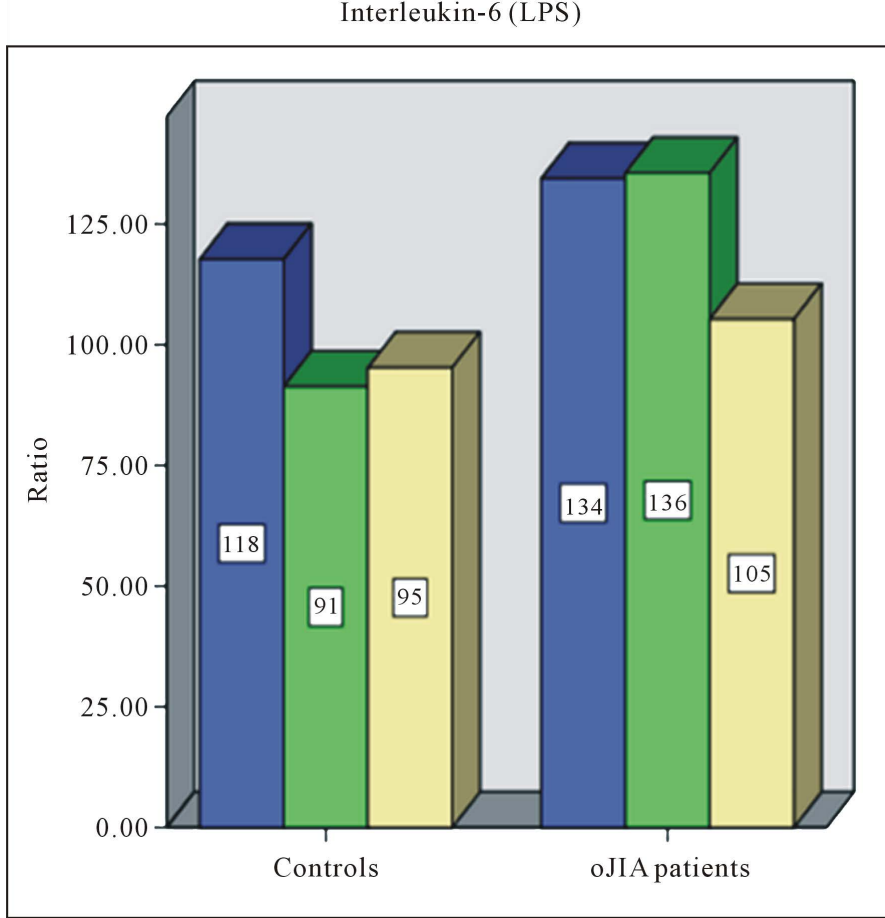

(b)

Tumor necrosis factor-alpha (LPS)

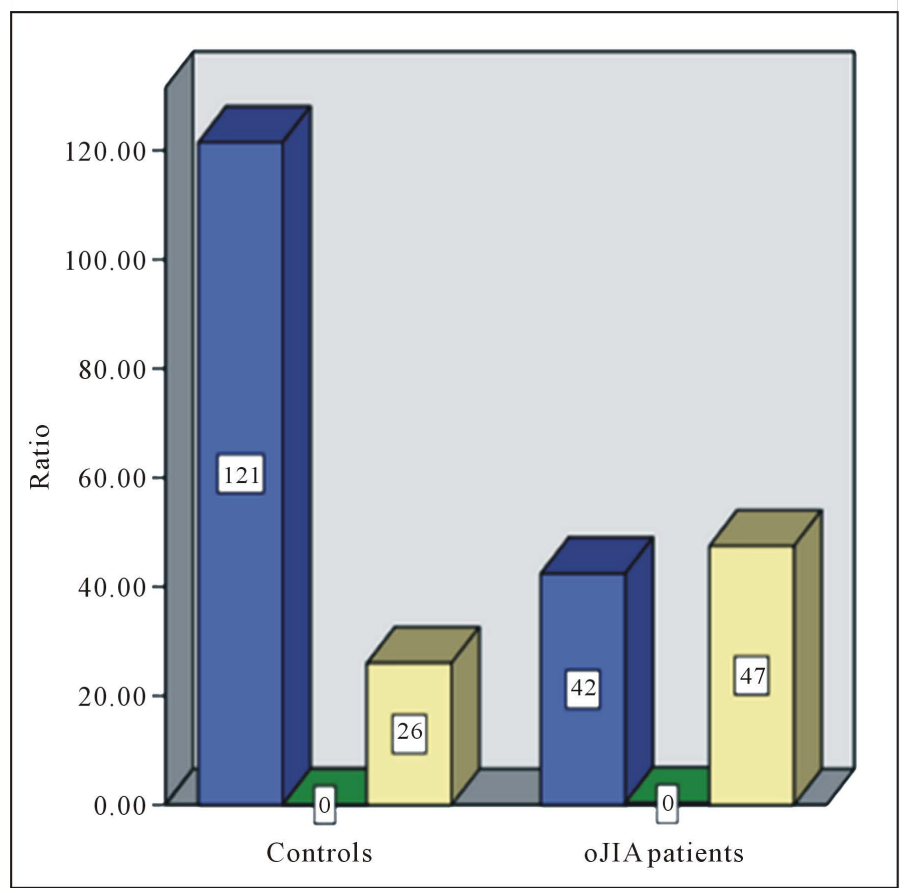

(c)
LPS stimulated/unstimulated

LPS stimulated adalimumab/unstimulated

LPS stimulated anakinra/unstimulated
LPS stimulated/unstimulated

LPS stimulated adalimumab/unstimulated

LPS stimulated anakinra/unstimulated

Figure 1. Representative bar diagrams showing the ratio of cytokine values of (a) IL-1, (b) IL-6 and (c) TNF- $\alpha$ in healthy controls (left) and oJIA patients (right). Blue filled bars: ratio of the values of LPS stimulated cell cultures and the values of unstimulated cell cultures. Green filled bars: ratio of the values of LPS stimulated cell cultures and the values of stimulated cell cultures with adalimumab. Purple filled bars: ratio of the values of LPS stimulated cell cultures and the values of stimulated cell cultures with etanercept. Yellow filled bars: ratio of the values of LPS stimulated cell cultures and the values of stimulated cell cultures with anakinra. 


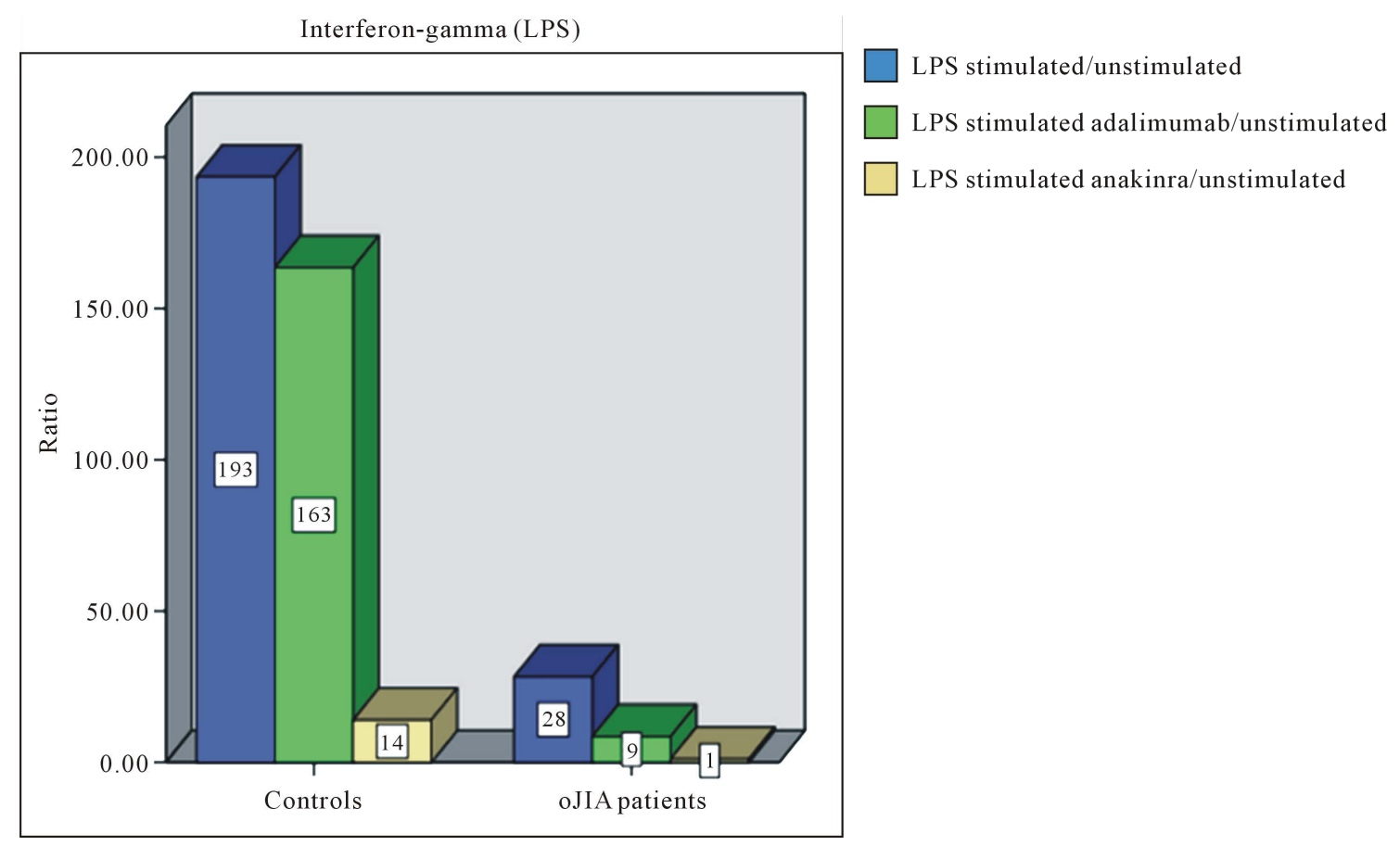

Figure 2. Representative bar diagrams showing the ratio of cytokine values of IFN- $\gamma$ in healthy controls (left) and oJIA patients (right). Blue filled bars: ratio of the values of LPS stimulated cell cultures and the values of unstimulated cell cultures. Green filled bars: ratio of the values of LPS stimulated cell cultures and the values of stimulated cell cultures with adalimumab. Purple filled bars: ratio of the values of LPS stimulated cell cultures and the values of stimulated cell cultures with etanercept. Yellow filled bars: ratio of the values of LPS stimulated cell cultures and the values of stimulated cell cultures with anakinra.

found this for IL-4. By contrast, stimulated leukocyte cultures of oJIA patients presented an increase of IL-4, even in cell cultures with adalimumab, etanercept or anakinra (Figure 3(a)).

LPS induced IL-10 production was generally higher in the control group. Furthermore, we observed in oJIA patients as well as in healthy controls a decrease of IL-10 in stimulated leukocyte cultures with anakinra. Adalimumab also reduces IL-10 levels, but only slightly and in oJIA patients (Figure 3(b)). On the contrary, etanercept seems to reinforce IL-10 secretion in both groups.

\section{Discussion}

Various types of immune cells, such as lymphocytes, macrophages and neutrophils, are involved in the development of joint inflammation. Toll-like receptors (TLRs) are a key link between infection, injury, and inflammation [37] Furthermore, a complex cytokine network is crucially implicated in the pathogenesis of oJIA. The enduring local inflammation in oJIA patients triggered by pathogen or damage-associated molecular patterns may correlate with levels of IL- 1 and TNF- $\alpha$ yield of leukocytes which are considered to be the basis for the emergence of tissue and joint damage. The macrophage cytokines TNF- $\alpha$ and IL-1 play an important role in inflammation and immune function [38]. They promote an inflammatory cascade, critical in the host response to infections and local injury. Additionally, in high concentrations, they may lead to excess inflammation and organ damage as seen in oJIA [39]. Cytokine inhibitors are thought to improve the patients clinical course by impairing the ability of TNF- $\alpha$ or IL-1 to bind to their receptors, inactivating the sepsis cascade cytokines, inhibiting production of inflammatory cytokines, and preventing further inflammation and damage to tissue or joints. However, this inhibition can potentially extend the susceptibility of patients to infections due to this downregulation of the immune system [40] [41].

The present study reveals selective alterations of leukocyte cytokine secretion of patients with oJIA compared to healthy control subjects after in vitro LPS stimulation and inhibition by anakinra, etanercept or adalimumab. Detectable imbalances of pro- and anti-inflammatory cytokines could give further hints for an improvement of 


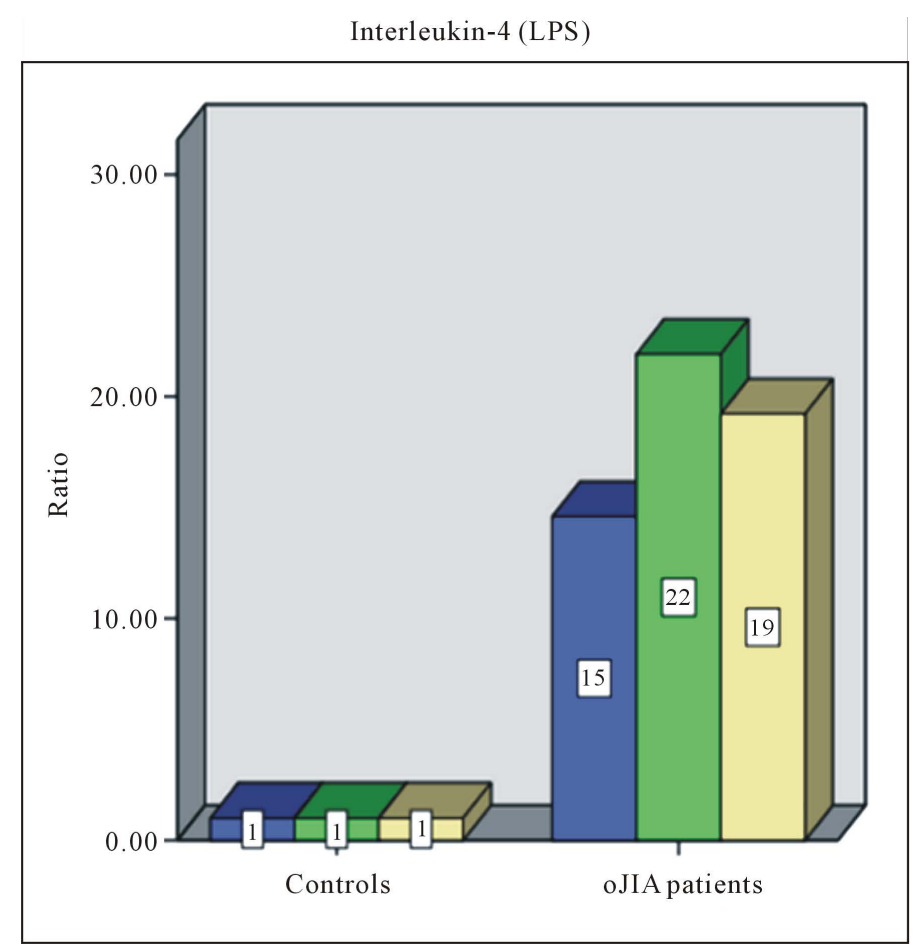

(a)

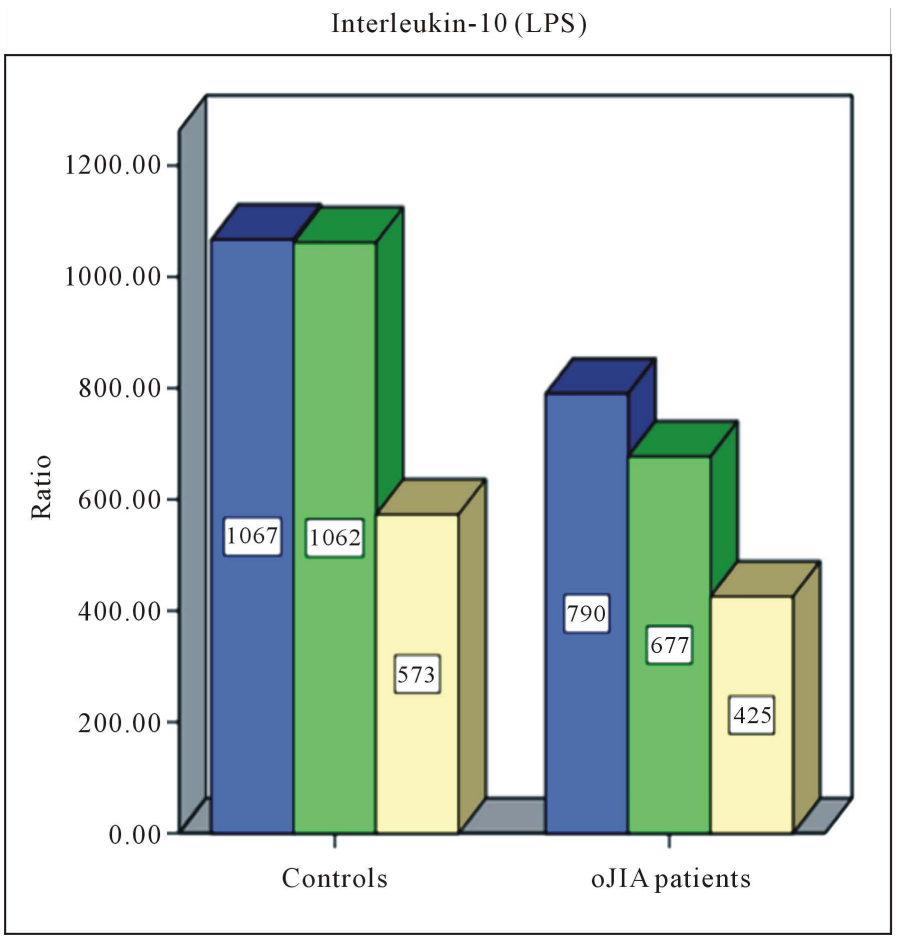

(b)
LPS stimulated/unstimulated

LPS stimulated adalimumab/unstimulated

LPS stimulated anakinra/unstimulated
LPS stimulated/unstimulated

LPS stimulated adalimumab/unstimulated

LPS stimulated anakinra/unstimulated

Figure 3. Representative bar diagrams showing the ratio of cytokine values of (a) IL-4 and (b) IL-10 in healthy controls (left) and oJIA patients (right). Blue filled bars: ratio of the values of LPS stimulated cell cultures and the values of unstimulated cell cultures. Green filled bars: ratio of the values of LPS stimulated cell cultures and the values of stimulated cell cultures with adalimumab. Purple filled bars: ratio of the values of LPS stimulated cell cultures and the values of stimulated cell cultures with etanercept. Yellow filled bars: ratio of the values of LPS stimulated cell cultures and the values of stimulated cell cultures with anakinra. 
therapeutic strategies for the treatment of oJIA.

LPS stimulation causes an increased expression of peptide/MHC complexes and molecules for T cell activation on the cell surface of dendritic cells and activates this cell population through a MyD88- and TRIF-dependent pathway [42]. This pathway results in the clonal expansion and differentiation of CD4 ${ }^{+} \mathrm{T}$ cells and thereby provides an important link between innate and acquired immunity [43]. From our former studies we know, that oJIA patients compared to healthy subjects show significantly higher levels of pro-inflammatory cytokines. Furthermore, we observed higher concentrations of the anti-inflammatory cytokine IL-10 in patients with oligoarthritis, seronegative polyarthritis and enthesitis related arthritis compared to healthy subjects [44].

In the course of our present study we also demonstrated that both, healthy and oJIA patients show a pro-inflammatory cytokine secretion after LPS stimulation: In both groups we detected an increased IL-6, TNF- $\alpha$, IL- $1 \beta$ and IFN- $\gamma$ production compared to the unstimulated control approach. In addition, the cytokine levels of healthy were higher than those of the oJIA patients. Moreover, we noticed a significantly higher IL-6 secretion of LPS stimulated leukocytes of oJIA patients compared with that of healthy control subjects. This finding supports the proposed role of pro-inflammatory IL-6 in the pathogenesis of oJIA: As is known, the concentration of IL-6 in synovial fluid and serum is increased in patients with oJIA compared to healthy and even correlated with disease activity [45]-[47]. In contrast to the results of de Jager et al. we found compared to healthy a lower concentration of IL-1 and no significant difference in TNF- $\alpha$ secretion [45]. The increase of the t cell cytokine IFN- $\gamma$ could be a correlate of activated $\mathrm{CD} 4{ }^{+} \mathrm{T}$ cells after LPS stimulation.

In consequence of LPS stimulation and TNF- $\alpha$ inhibition by adalimumab, the target cytokine TNF- $\alpha$ fell just below the detection limit. The cytokine levels of IL-1 and IFN- $\gamma$ were also reduced. These results met for patients and healthy and probably reflect a decreased macrophage activity. This reduced amount of IFN- $\gamma$ fits the observation, that TNF- $\alpha$ as a result of an increasing production of IL-12 and IL-18 normally leads to multiplied secretion of IFN- $\gamma$ in children with oJIA [48].

In our in vitro model, we demonstrated that blockade of TNF- $\alpha$ could result in a diminished IFN- $\gamma$ production. IFN- $\gamma$ is formed mainly by Th1 cells, activated monocytes and macrophages. Subsequently, the production and secretion of IL- $1 \beta$ is started, while the formation of anti-inflammatory Th2 cytokines IL-4 and IL-10 is inhibited the same time [49] [50]. Our results show that the inhibition of TNF- $\alpha$ leads to an increased concentration of IL-4 at oJIA patients. This could be mediated directly by the lack of effect of TNF- $\alpha$, or may be the result of the reduced IFN- $\gamma$ secretion [43].

Under LPS stimulation, the inhibition of TNF- $\alpha$ by the receptor fusion protein etanercept caused in oJIA affected children an increased concentration of TNF- $\alpha$ in vitro. This result is confirmed by the in vivo studies of Mohler et al.: the researchers found in mice after administration of a synthetic dimeric sTNFR: Fc (structurally similar to etanercept) and LPS stimulation an increase of the serum concentration of TNF- $\alpha$ [51]. Additionally, LPS stimulated leukocytes of both, patients and healthy individuals, produced less IL- 6 and IL- $1 \beta$ after administration of etanercept. We consider this as an indication of an effective suppression of inflammation, which is mediated by the cells of the innate immune system. An anti-inflammatory effect, which we have already seen in leukocyte cultures with adalimumab was the increased concentration of IL-4 (respectively IL-10) after LPS stimulation and administration of etanercept.

Adult studies have, for the most part, shown that TNF- $\alpha$ antagonists lead to an increased risk of opportunistic infections and serious infections, when compared to other disease-modifying antirheumatic drugs [52]-[54]. Despite the extensive use of biologics in pediatrics, it remains unclear whether there is a similarly increased risk of infections and what types of infections occur. To date, studies in children with oJIA treated with TNF- $\alpha$ inhibitors have considered of small subject numbers, with outcomes mostly focused on drug efficacy or serious adverse events [55]-[57]. Bracaglia et al. reported that JIA patients can frequently develop mild infections and, less commonly, severe infections when treated with etanercept or adalimumab [56]. As described above, we found as a consequence of LPS stimulation and TNF- $\alpha$ inhibition by adalimumab respectively etanercept, reduced levels of IL-1 and IFN- $\gamma$. Importantly, it is unknown whether JIA itself further contributes to an increased risk of infection.

In addition to TNF- $\alpha$, other pro-inflammatory cytokines of the innate immune system are involved in the pathogenesis of oJIA. Lotito et al. detected higher concentrations of IL- $1 \beta$ in patients with oJIA than in their control group [47]. We confirmed this in our in vitro model. Even in the unstimulated cell culture approaches of oJIA patients we found higher amounts of IL- $1 \beta$ than in the approaches of healthy individuals. Thus, the cytokine IL- $1 \beta$ is a potential target in therapeutic intervention of oJIA. Inhibition of IL- $1 \beta$ by the IL- 1 receptor an- 
tagonist, anakinra, led after LPS stimulation to a reduced concentration of IL- $1 \beta$ in both, healthy and oJIA children. The concentration of the pro-inflammatory cytokine IL-6 was decreased by LPS stimulation in both groups, suggesting a similar role in the sequence of inflammatory events after administration of anakinra. The inhibition of IL- $1 \beta$ seems to suppress the activation of $\mathrm{CD} 4^{+}$Th1 cells: After LPS stimulation and administration of anakinra, a decrease of IFN- $\gamma$ was observed. Unfortunately, based on our in vitro model it can not be displayed whether this leads to a real inhibition of $\mathrm{T}$ cells. The aforementioned suppression of pro-inflammatory cytokines by anakinra was supported in the group of oJIA patients by an increase of IL-4, in healthy individuals there was no detectable concentration of this cytokine.

After LPS stimulation and administration of ankinra patients with oJIA showed an increase in the concentration of pro-inflammatory cytokine TNF- $\alpha$. Here, the group of oJIA patients differed significantly from healthy individuals, which showed a reduced concentration of this cytokine after the administration of the IL-1 receptor antagonist. In both groups there was a lower concentration of IL-10. Thus, for oJIA patients as a result of IL-1 $\beta$ inhibition an increase of TNF- $\alpha$ can be documented.

In our opinion, this must be seen as a state of persistent inflammation. In this context the group of healthy individuals showed decreasing pro-inflammatory cytokines. This is a further indication that the cytokine network of oJIA patients is fundamentally different from that of healthy subjects.

\section{Conclusions}

To conclude, our observations suggest that the selective inhibition of cytokines affects the entire cytokine network of oJIA patients. We describe a shift from pro-inflammation to anti-inflammation, which is mediated by the fading of pro-inflammation and the rise of anti-inflammatory cytokines. However, the concentration of individual pro-inflammatory cytokines remains elevated even after the administration of biologics. This could arise as an explanatory model for the emergence of drug-resistant disease conditions. Only the precise knowledge of the cytokine network of oJIA patients allows a targeted therapy.

The allocation of specific cytokine patterns to individual subtypes of JIA allows appropriate control of these parameters in the course of the disease and provides an indication of which biologic drug should be used in therapy. For therapeutic follow-up individual measurements of cytokine concentrations are conceivable. For example, further prospective studies with larger patient populations, more frequent follow-up, and more thorough assessment of mild and serious infections would significantly help clinicians better understand the implications of starting a patient with JIA on cytokine inhibitors, and ultimately help to improve prevention strategies and management.

Further observational research using disease registries and cohort studies may provide additional evidence on the clinical benefits of various treatment pathways and safety issues over the long-term. Supporting research in the use of biomarker-based diagnostic and risk prediction tools may also help children with JIA to receive the most effective and safest choice of therapy.

\section{References}

[1] Berkun, Y. and Padeh, S. (2010) Environmental Factors and the Geoepidemiology of Juvenile Idiopathic Arthritis. Autoimmunity Reviews, 9, A319-A324. http://dx.doi.org/10.1016/j.autrev.2009.11.018

[2] Kaminiarczyk-Pyzalka, D., Adamczak, K., Mikos, H., Klimecka, I., Moczko, J. and Niedziela, M. (2014) Serum TNFAlpha Levels and Indicators of Disease Activity in Children with Oligoarticular Juvenile Idiopathic Arthritis (oJIA) in the First Year of the Disease. Clinical Laboratory, 60, 799-807.

[3] Muzaffer, M.A., et al. (2002) Differences in the Profiles of Circulating Levels of Soluble Tumor Necrosis Factor Receptors and Interleukin 1 Receptor Antagonist Reflect the Heterogeneity of the Subgroups of Juvenile Rheumatoid Arthritis. The Journal of Rheumatology, 29, 1071-1078.

[4] Woo, P. (2002) Cytokines and Juvenile Idiopathic Arthritis. Current Rheumatology Reports, 4, 452-457. http://dx.doi.org/10.1007/s11926-002-0050-9

[5] Beukelman, T., Patkar, N.M., Saag, K.G., Tolleson-Rinehart, S., Cron, R.Q., De Witt, E.M., et al. (2011) American College of Rheumatology Recommendations for the Treatment of Juvenile Idiopathic Arthritis: Initiation and Safety Monitoring of Therapeutic Agents for the Treatment of Arthritis and Systemic Features. Arthritis Care \& Research, 63, 465-482. http://dx.doi.org/10.1002/acr.20460

[6] Mattey, D.L., Packham, J.C., Nixon, N.B., Coates, L., Creamer, P., Hailwood, S., et al. (2012) Association of Cytokine and Matrix Metalloproteinase Profiles with Disease Activity and Function in Ankylosing Spondylitis. Arthritis Re- 
search \& Therapy, 14, R127. http://dx.doi.org/10.1186/ar3857

[7] Prakken, B.J., Roord, S., Ronaghy, A., Wauben, M., Albani, S. and van Eden, W. (2003) Heat Shock Protein 60 and Adjuvant Arthritis: A Model for T Cell Regulation in Human Arthritis. Springer Seminars in Immunopathology, 25, 47-63. http://dx.doi.org/10.1007/s00281-003-0128-7

[8] Gerss, J., Roth, J., Holzinger, D., Ruperto, N., Wittkowski, H., Frosch, M., Wulffraat, N., et al. (2012) PhagocyteSpecific S100 Proteins and High-Sensitivity C Reactive Protein as Biomarkers for a Risk-Adapted Treatment to Maintain Remission in Juvenile Idiopathic Arthritis: A Comparative Study. Annals of the Rheumatic Diseases, 71, 19911997. http://dx.doi.org/10.1136/annrheumdis-2012-201329

[9] Holzinger, D., Frosch, M., Kastrup, A., Prince, F.H.M., Otten, M.H., et al. (2012) The Toll-Like Receptor 4 Agonist MRP8/14 Protein Complex Is a Sensitive Indicator for Disease Activity and Predicts Relapses in Systemic-Onset Juvenile Idiopathic Arthritis. Annals of the Rheumatic Diseases, 71, 974-980. http://dx.doi.org/10.1136/annrheumdis-2011-200598

[10] Scardapane, A., Breda, L., Lucantoni, M. and Chiarelli, F. (2012) TNF-Alpha Polymorphisms in Juvenile Idiopathic Arthritis: Which Potential Clinical Implications? International Journal of Rheumatology, 2012, 756291. http://dx.doi.org/10.1155/2012/756291

[11] Ravelli, A. and Martini, A. (2007) Juvenile Idiopathic Arthritis. Lancet, 369, 767-778. http://dx.doi.org/10.1016/S0140-6736(07)60363-8

[12] Zeggini, E., Thomson, W., Kwiatkowski, D., Richardson, A., Ollier, W., Donn, R., et al. (2002) Linkage and Association Studies of Single-Nucleotide Polymorphism-Tagged Tumor Necrosis Factor Haplotypes in Juvenile Oligoarthritis. Arthritis and Rheumatism, 46, 3304-3311. http://dx.doi.org/10.1002/art.10698

[13] Schmeling, H., Wagner, U., Peterson, A. and Horneff, G. (2006) Tumor Necrosis Factor Alpha Promoter Polymorphisms in Patients with Juvenile Idiopathic Arthritis. Clinical and Experimental Rheumatology, 24, 103-108.

[14] Mourao, A.F., et al. (2009) Tumor Necrosis Factor-Alpha-308 Genotypes Influence Inflammatory Activity and TNFAlpha Serum Concentrations in Children with Juvenile Idiopathic Arthritis. The Journal of Rheumatology, 36, 837842.

[15] Jimenez-Morales, S., Velázquez-Cruz, R., Ramírez-Bello, J., Bonilla-Gonzálezb, E., Romero-Hidalgoc, S., et al. (2009) Tumor Necrosis Factor-Alpha Is a Common Genetic Risk Factor for Asthma, Juvenile Rheumatoid Arthritis, and Systemic Lupus Erythematosus in a Mexican Pediatric Population. Human Immunology, 70, 251-256. http://dx.doi.org/10.1016/j.humimm.2009.01.027

[16] Modesto, C., Patiño-García, A., Sotillo-Piñeiro, E., Merino, J., García-Consuegra, J., Merino, R., Rua, M.J., Sierrasesúmaga, L. and Arnal, C. (2005) TNF- $\alpha$ Promoter Gene Polymorphisms in Spanish Children with Persistent Oligoarticular and Systemic-Onset Juvenile Idiopathic Arthritis. Scandinavian Journal of Rheumatology, 34, 451-454. http://dx.doi.org/10.1080/03009740510026652

[17] Schmeling, H. and Horneff, G. (2007) Tumour Necrosis Factor Alpha Promoter Polymorphisms and Etanercept Therapy in Juvenile Idiopathic Arthritis. Rheumatology International, 27, 383-386. http://dx.doi.org/10.1007/s00296-006-0208-2

[18] Huizinga, T.W., Westendorp, R.G.J., Bollen, E.L.E.M., Keijsers, V., Brinkman, B.M.N., Langermans, J.A.M., et al. (1997) TNF- $\alpha$ Promoter Polymorphisms, Production and Susceptibility to Multiple Sclerosis in Different Groups of Patients. Journal of Neuroimmunology, 72, 149-153. http://dx.doi.org/10.1016/S0165-5728(96)00182-8

[19] Hohler, T., Kruger, A., Schneider, P.M., Schopf, R.E., Knop, J., Rittner, C., zum Büschenfelde, K.H.M. and MärkerHermann, E. (1997) A TNF- $\alpha$ Promoter Polymorphism Is Associated with Juvenile Onset Psoriasis and Psoriatic Arthritis. The Journal of Investigative Dermatology, 109, 562-565. http://dx.doi.org/10.1111/1523-1747.ep12337469

[20] Havemose-Poulsen, A., Sorensen, L.K., Stoltze, K., Bendtzen, K. and Holmstrup, P. (2005) Cytokine Profiles in Peripheral Blood and Whole Blood Cell Cultures Associated with Aggressive Periodontitis, Juvenile Idiopathic Arthritis, and Rheumatoid Arthritis. Journal of Periodontology, 76, 2276-2285. http://dx.doi.org/10.1902/jop.2005.76.12.2276

[21] Ruth, N.M. and Passo, M.H. (2012) Juvenile Idiopathic Arthritis: Management and Therapeutic Options. Therapeutic Advances in Musculoskeletal Disease, 4, 99-110.

[22] Lee, J.H., Slifman, N.R., Gershon, S.K., Edwards, E.T., Schwieterman, W.D., Siegel, J.N., Wise, R.P., Lori Brown, S., Udall Jr., J.N. and Miles Braun, M. (2002) Life-Threatening Histoplasmosis Complicating Immunotherapy with Tumor Necrosis Factor $\alpha$ Antagonists Infliximab and Etanercept. Arthritis and Rheumatism, 46, 2565-2570. http://dx.doi.org/10.1002/art.10583

[23] Kalliolias, G.D. and Liossis, S.N. (2008) The Future of the IL-1 Receptor Antagonist Anakinra: From Rheumatoid Arthritis to Adult-Onset Still's Disease and Systemic-Onset Juvenile Idiopathic Arthritis. Expert Opinion on Investigational Drugs, 17, 349-359. http://dx.doi.org/10.1517/13543784.17.3.349

[24] Furst, D.E., Breedveld, F.C., Kalden, J.R., Smolen, J.S., Burmester, G.R., Sieper, J., Emery, P., et al. (2007) Updated 
Consensus Statement on Biological Agents for the Treatment of Rheumatic Diseases, 2007. Annals of the Rheumatic Diseases, 66, iii2-iii22. http://dx.doi.org/10.1136/ard.2007.081430

[25] Horneff, G. (2006) Biologics for Treatment of Juvenile Idiopathic Arthritis. Consensus Statement of the 7th Worlitzer Expertengesprache 2004 for the German Arbeitsgemeinschaft Kinder- und Jugendrheumatologie. Zeitschrift fur Rheumatologie, 65, 152-156, 158.

[26] Sharma, R., Sharma, C.L. and Mahajan, A. (2008) Biological Agents Targeting beyond TNF-Alpha. Indian Journal of Critical Care Medicine: Peer-Reviewed, Official Publication of Indian Society of Critical Care Medicine, 12, 181-189.

[27] Greenberg, J.D., Reed, G., Kremer, J.M., Tindall, E., Kavanaugh, A., Zheng, C., Bishai, W. and Hochberg, M.C. (2010) Association of Methotrexate and Tumour Necrosis Factor Antagonists with Risk of Infectious Outcomes Including Opportunistic Infections in the CORRONA Registry. Annals of the Rheumatic Diseases, 69, 380-386. http://dx.doi.org/10.1136/ard.2008.089276

[28] Smith, J.A. and Kauffman, C.A. (2009) Endemic Fungal Infections in Patients Receiving Tumour Necrosis Factor- $\alpha$ Inhibitor Therapy. Drugs, 69, 1403-1415. http://dx.doi.org/10.2165/00003495-200969110-00002

[29] Jackson, J.M. (2007) TNF- $\alpha$ Inhibitors. Dermatologic Therapy, 20, 251-264. http://dx.doi.org/10.1111/j.1529-8019.2007.00138.x

[30] Hess, S., Hospach, T., Nossal, R., Dannecker, G., Magdorf, K. and Uhlemann, F. (2011) Life-Threatening Disseminated Tuberculosis as a Complication of TNF- $\alpha$ Blockade in an Adolescent. European Journal of Pediatrics, 170, 1337-1342. http://dx.doi.org/10.1007/s00431-011-1501-y

[31] Grainger, R. and Harrison, A. (2005) TNF Inhibitors for Inflammatory Arthritis in New Zealand. The New Zealand Medical Journal, 118, U1706.

[32] Fleischmann, R., Iqbal, I., Nandeshwar, P. and Quiceno, A. (2002) Safety and Efficacy of Disease-Modifying AntiRheumatic Agents: Focus on the Benefits and Risks of Etanercept. Drug Safety: An International Journal of Medical Toxicology and Drug Experience, 25, 173-197.

[33] Adib, N., Silman, A. and Thomson, W. (2005) Outcome Following Onset of Juvenile Idiopathic Inflammatory Arthritis: I. Frequency of Different Outcomes. Rheumatology, 44, 995-1001. http://dx.doi.org/10.1093/rheumatology/keh620

[34] Diak, P., Siegel, J., La Grenade, L., Choi, L., Lemery, S. and McMahon, A. (2010) Tumor Necrosis Factor $\alpha$ Blockers and Malignancy in Children: Forty-Eight Cases Reported to the Food and Drug Administration. Arthritis \& Rheumatism, 62, 2517-2524. http://dx.doi.org/10.1002/art.27511

[35] Hashkes, P.J., Uziel, Y. and Laxer, R.M. (2010) The Safety Profile of Biologic Therapies for Juvenile Idiopathic Arthritis. Nature Reviews. Rheumatology, 6, 561-571.

[36] Horneff, G., Foeldvari, I., Minden, K., Moebius, D. and Hospach, T. (2011) Report on Malignancies in the German Juvenile Idiopathic Arthritis Registry. Rheumatology, 50, 230-236. http://dx.doi.org/10.1093/rheumatology/keq361

[37] Tapping, R.I. (2009) Innate Immune Sensing and Activation of Cell Surface Toll-Like Receptors. Seminars in Immunology, 21, 175-184. http://dx.doi.org/10.1016/j.smim.2009.05.003

[38] Yao, T.C., Kuo, M.L., See, L.C., Ou, L.S., Lee, W.I., Chan, C.K. and Huang, J.L. (2006) RANTES and Monocyte Chemoattractant Protein 1 as Sensitive Markers of Disease Activity in Patients with Juvenile Rheumatoid Arthritis: A Six-Year Longitudinal Study. Arthritis and Rheumatism, 54, 2585-2593. http://dx.doi.org/10.1002/art.21962

[39] Murphy, C.A., Langrish, C.L., Chen, Y., Blumenschein, W., McClanahan, T., Kastelein, R.A., Sedgwick, J.D. and Cua, D.J. (2003) Divergent Pro- and Antiinflammatory Roles for IL-23 and IL-12 in Joint Autoimmune Inflammation. The Journal of Experimental Medicine, 198, 1951-1957. http://dx.doi.org/10.1084/jem.20030896

[40] Roach, D.R., Bean, A.G.D., Demangel, C., France, M.P., Briscoe, H. and Britton, W.J. (2002) TNF Regulates Chemokine Induction Essential for Cell Recruitment, Granuloma Formation, and Clearance of Mycobacterial Infection. Journal of Immunology, 168, 4620-4627. http://dx.doi.org/10.4049/jimmunol.168.9.4620

[41] Toussi, S.S., Pan, N., Walters, H.M. and Walsh, T.J. (2013) Infections in Children and Adolescents with Juvenile Idiopathic Arthritis and Inflammatory Bowel Disease Treated with Tumor Necrosis Factor- $\alpha$ Inhibitors: Systematic Review of the Literature. Clinical Infectious Diseases: An Official Publication of the Infectious Diseases Society of America, 57, 1318-1330.

[42] McAleer, J.P. and Vella, A.T. (2010) Educating CD4 T Cells with Vaccine Adjuvants: Lessons from Lipopolysaccharide. Trends in Immunology, 31, 429-435. http://dx.doi.org/10.1016/j.it.2010.08.005

[43] Tamura, T., Yanai, H., Savitsky, D. and Taniguchi, T. (2008) The IRF Family Transcription Factors in Immunity and Oncogenesis. Annual Review of Immunology, 26, 535-584. http://dx.doi.org/10.1146/annurev.immunol.26.021607.090400

[44] Kirchner, M., Sonnenschein, A., Schoofs, S., Schmidtke, P., Umlauf, V.N. and Mannhardt-Laakmann, W. (2013) Surface Expression and Genotypes of Toll-Like Receptors 2 and 4 in Patients with Juvenile Idiopathic Arthritis and Sys- 
temic Lupus Erythematosus. Pediatric Rheumatology, 11, 9. http://dx.doi.org/10.1186/1546-0096-11-9

[45] de Jager, W., Hoppenreijs, E.P.A.H., Wulffraat, N.M., Wedderburn, L.R., Kuis, W. and Prakken, B.J. (2007) Blood and Synovial Fluid Cytokine Signatures in Patients with Juvenile Idiopathic Arthritis: A Cross-Sectional Study. Annals of the Rheumatic Diseases, 66, 589-598. http://dx.doi.org/10.1136/ard.2006.061853

[46] Yilmaz, M., Kendirli, S.G., Altintas, D., Bingol, G. and Antmen, B. (2001) Cytokine Levels in Serum of Patients with Juvenile Rheumatoid Arthritis. Clinical Rheumatology, 20, 30-35. http://dx.doi.org/10.1007/s100670170100

[47] Lotito, A.P., Campa, A., Silva, C.A., Kiss, M.H. and Mello, S.B. (2007) Interleukin 18 as a Marker of Disease Activity and Severity in Patients with Juvenile Idiopathic Arthritis. The Journal of Rheumatology, 34, 823-830.

[48] Wedderburn, L.R., Robinson, N., Patel, A., Varsani, H. and Woo, P. (2000) Selective Recruitment of Polarized T Cells Expressing CCR5 and CXCR3 to the Inflamed Joints of Children with Juvenile Idiopathic Arthritis. Arthritis and Rheumatism, 43, 765-774. http://dx.doi.org/10.1002/1529-0131(200004)43:4<765::AID-ANR7>3.0.CO;2-B

[49] Gattorno, M., Prigione, I., Morandi, F., Gregorio, A., Chiesa, S., Ferlito, F., et al. (2005) Phenotypic and Functional Characterisation of CCR7 ${ }^{+}$and CCR7 ${ }^{-} \mathrm{CD}^{+}$Memory T Cells Homing to the Joints in Juvenile Idiopathic Arthritis. Arthritis Research \& Therapy, 7, R256-R267. http://dx.doi.org/10.1186/ar1485

[50] Agarwal, S., Misra, R. and Aggarwal, A. (2008) Interleukin 17 Levels Are Increased in Juvenile Idiopathic Arthritis Synovial Fluid and Induce Synovial Fibroblasts to Produce Proinflammatory Cytokines and Matrix Metalloproteinases. The Journal of Rheumatology, 35, 515-519.

[51] Mohler, K.M., Torrance, D.S., Smith, C.A., Goodwin, R.G., Stremler, K.E., Fung, V.P., Madani, H. and Widmer, M.B. (1993) Soluble Tumor Necrosis Factor (TNF) Receptors Are Effective Therapeutic Agents in Lethal Endotoxemia and Function Simultaneously as both TNF Carriers and TNF Antagonists. Journal of Immunology, 151, 1548-1561.

[52] Martin-Mola, E. and Balsa, A. (2009) Infectious Complications of Biologic Agents. Rheumatic Disease Clinics of North America, 35, 183-199. http://dx.doi.org/10.1016/j.rdc.2009.03.009

[53] Favalli, E.G., Desiati, F., Atzeni, F., Sarzi-Puttini, P., Caporali, R., Pallavicini, F.B., Gorla, R., Filippini, M. and Marchesoni, A. (2009) Serious Infections during Anti-TNFa Treatment in Rheumatoid Arthritis Patients. Autoimmunity Reviews, 8, 266-273. http://dx.doi.org/10.1016/j.autrev.2008.11.002

[54] Strangfeld, A., Listing, J., Herzer, P., Liebhaber, A., Rockwitz, K., Richter, C. and Zink, A. (2009) Risk of Herpes Zoster in Patients with Rheumatoid Arthritis Treated with Anti-TNFa Agents. JAMA: The Journal of the American Medical Association, 301, 737-744. http://dx.doi.org/10.1001/jama.2009.146

[55] Mori, M., Takei, S., Imagawa, T., Imanaka, H., Nerome, Y., Higuchi, R., et al. (2012) Safety and Efficacy of LongTerm Etanercept in the Treatment of Methotrexate-Refractory Polyarticular-Course Juvenile Idiopathic Arthritis in Japan. Modern Rheumatology/the Japan Rheumatism Association, 22, 720-726.

[56] Bracaglia, C., Buonuomo, P.S., Tozzi, A.E., Pardeo, M., Nicolai, R., Campana, A., Insalaco, A., Cortis, E. and de Benedetti, F. (2012) Safety and Efficacy of Etanercept in a Cohort of Patients with Juvenile Idiopathic Arthritis under 4 Years of Age. The Journal of Rheumatology, 39, 1287-1290. http://dx.doi.org/10.3899/jrheum.111555

[57] Tzaribachev, N., Kuemmerle-Deschner, J., Eichner, M. and Horneff, G. (2008) Safety and Efficacy of Etanercept in Children with Juvenile Idiopathic Arthritis below the Age of 4 Years. Rheumatology International, 28, 1031-1034. http://dx.doi.org/10.1007/s00296-008-0563-2 
Scientific Research Publishing (SCIRP) is one of the largest Open Access journal publishers. It is currently publishing more than 200 open access, online, peer-reviewed journals covering a wide range of academic disciplines. SCIRP serves the worldwide academic communities and contributes to the progress and application of science with its publication.

Other selected journals from SCIRP are listed as below. Submit your manuscript to us via either submit@scirp.org or Online Submission Portal.
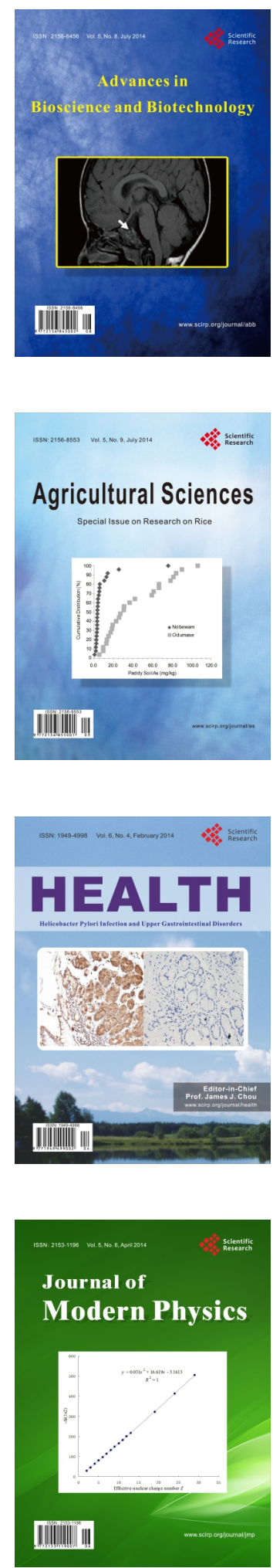
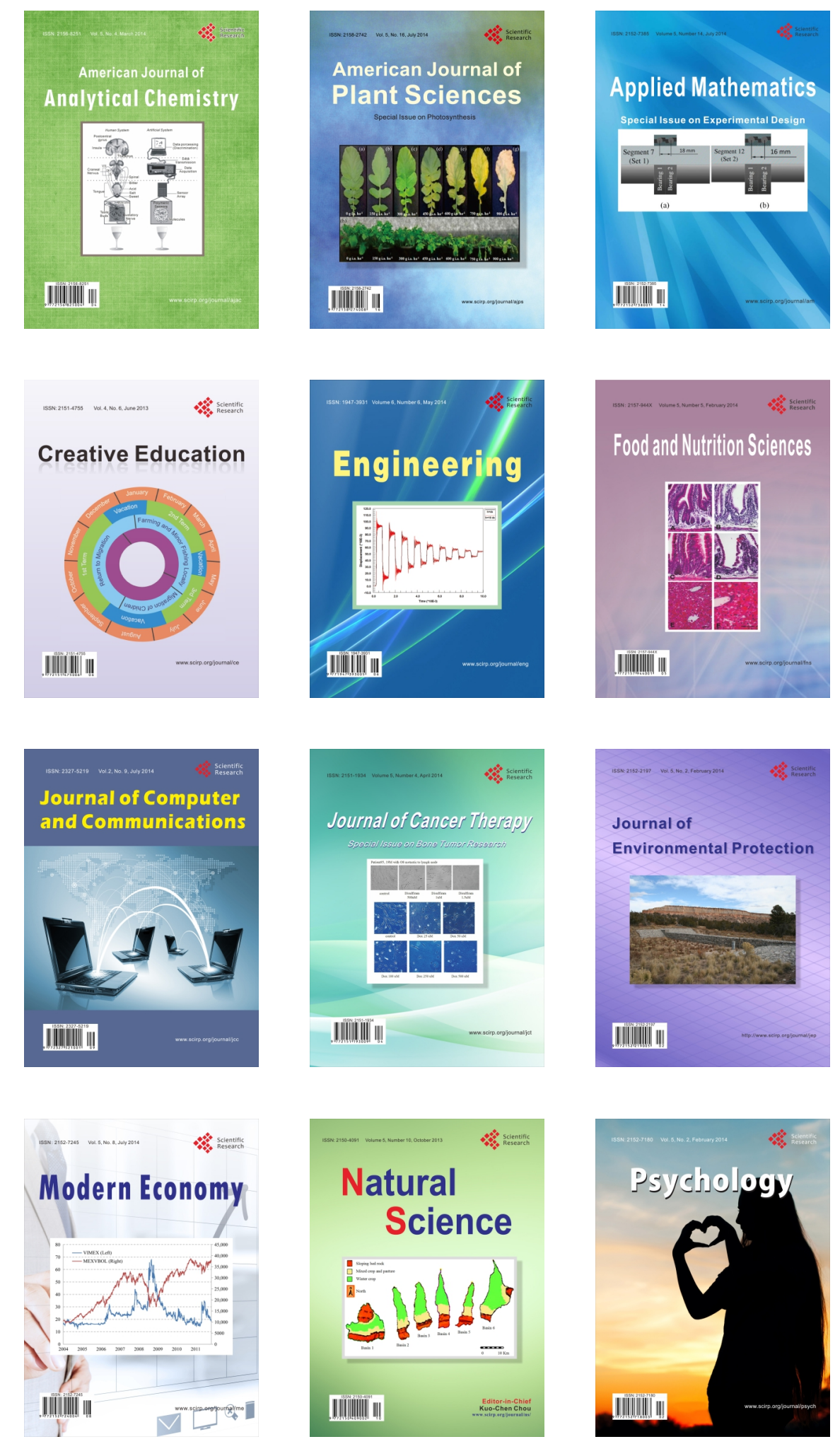